\title{
Antiecologismo no Congresso Nacional: o meio ambiente representado na Câmara dos Deputados e no Senado Federal
}

\section{Anti-Environmentalism in Brazilian Congress: The Environment in the House of Representatives and Senate}

\author{
Inny ACCIOLY* \\ Celso SÁNCHEZ**
}

\begin{abstract}
RESUMO
A pesquisa investiga a existência de um "movimento antiecológico" no interior do Congresso Nacional, a natureza dos protagonistas e destinatários do movimento, assim como analisa as suas estratégias de ação e o grau de periculosidade destas. Visto que a Câmara dos Deputados "compõe-se de representantes do povo" e o Senado Federal "compõe-se de representantes dos Estados e do Distrito Federal", entende-se que este movimento encontra apoio em parcelas significativas da população e que suas estratégias têm obtido resultados. O trabalho foi realizado através do levantamento de dados de financiamento de campanha de parlamentares ligados a Comissões de Meio Ambiente, assim como seus posicionamentos manifestos na mídia. Observamos que nas campanhas eleitorais dos parlamentares estudados, atuaram como financiadoras empresas ligadas ao agronegócio e que respondem a processos ambientais e trabalhistas. Foi também possível constatar a desigualdade de forças entre o grupo "antiecológico" e o grupo ambientalista.
\end{abstract}

Palavras-chave: movimento antiecológico; Congresso Nacional; políticas ambientais.

\begin{abstract}
The research investigates the existence of a strong "anti-environmental movement" inside the Brazilian Congress, the nature of the protagonists and recipients of the movement, as well as analyzes their strategies and their degree of dangerousness. Since the House of Representatives "is composed of representatives of the people" and the Senate "is composed of representatives of states and the Federal District", it means that this movement finds support in significant portions of the population and that their strategies have obtained results. The study was conducted through data collection from campaign financing from the related parliamentary members of committees on the environment and their positions manifested
\end{abstract}

\footnotetext{
*Especialista em Educação Ambiental (PUC-Rio) e mestranda do Programa de Pós Graduação em Educação da Universidade Federal do Rio de Janeiro (UFRJ). Pesquisadora do Laboratório de Investigações em Educação, Ambiente e Sociedade (LIEAS-UFRJ). Email: innyaccioly@hotmail.com

"* Doutor em Educação (PUC-Rio). Professor do Departamento de Didática da Escola de Educação e Pesquisador do NGA (Núcleo de Gestão Ambiental) da Universidade Federal do Estado do Rio de Janeiro (UNIRIO). Email: celsosanchez@unirio.br
} 
in the media. We observed that in the parliamentary election campaigns many companies involved in agribusiness and responding to environmental and labor processes acted as donors. It was also possible to verify the inequality of power between the "anti-ecological" group and the environmental group.

Keywords: anti-environmental movement; Brazilian Congress; environmental policies.

\section{Introdução}

\section{O meio ambiente existe para prover o ser humano de suas necessidades básicas de sobrevivência. É dele que tira alimento, remédios, vestuário e outros insumos que lhe garantem saúde, conhecimento, progresso e bem-estar. ${ }^{1}$}

No atual momento de revisão das políticas ambientais brasileiras, torna-se de extrema importância para a Educação Ambiental Crítica a discussão acerca da pluralidade e da heterogeneidade de posicionamentos em relação ao debate ambientalista no âmbito das Comissões de Meio Ambiente e temas correlatos no Congresso Nacional. ${ }^{2}$

A pesquisa pretende investigar a existência de um "movimento antiecológico" no interior do Congresso Nacional, a natureza dos protagonistas e destinatários do movimento, assim como analisar as suas estratégias de ação e o grau de periculosidade destas. Visto que a Câmara dos Deputados "compõe-se de representantes do povo" e o Senado Federal "compõe-se de representantes dos Estados e do Distrito Federal" (BRASIL, 1989), entende-se que este movimento encontra apoio em parcelas significativas da população e que suas estratégias têm obtido resultados.

Apoiados nos pressupostos de uma Educação Ambiental Crítica (LOUREIRO, 2009) e "de inserção lúcida na realidade, na situação histórica" (FREIRE, 2005, p. 61), procuramos problematizar o atual contexto político brasileiro, onde são elaboradas e votadas leis ambientais, sob uma perspectiva que busca "apreender os aspectos e momentos contraditórios, a coisa como totalidade e unidade de contraditórios" (GADOTTI, 2004, p. 113), encorajando o leitor a tecer suas próprias conclusões a partir da análise de conjuntura apresentada.

Uma vez que a ideia de "natureza" engendra posicionamentos distintos e distintas formas de representação, urge ressaltar que o movimento ambientalista atual, apesar das aparências, não pode se caracterizar pela unicidade de atuação e de motivações ideológicas. ${ }^{3}$ (LAYRARGUES, 1998).

Ao identificar o movimento "antiecológico" que vem ganhando espaço no campo da política brasileira, pretendemos desconstruir a falsa noção de que as ideias e práticas da sustentabilidade presentes na sociedade contemporânea se expandem como uma "onda", contaminando todos os sujeitos sociais indistintamente, sem encontrar resistências e obstáculos.

Este debate é particularmente útil no campo da Educação Ambiental, que tem entre suas visões hegemônicas a que reproduz uma concepção de sociedade como espaço da harmonia e ausência de conflitos e interesses, com a ideia de que a sociedade como um todo, ao passar pelo processo educativo voltado à questão ambiental, naturalmente passaria por uma conversão em direção à sustentabilidade, como se a questão tratasse apenas de um processo de conscientização (LAYRARGUES, 2010).

\section{Metodologia}

Para investigar o fenômeno "antiecologismo" na sociedade brasileira - fenômeno de negação da dimensão ambiental, que se expressa concretamente em uma sociedade onde os discursos governamentais pendem para a "economia verde" e a "sustentabilidade" - utilizamos como

\footnotetext{
${ }^{1}$ Kátia Abreu, Senadora da República pelo DEM-TO, Vice-Presidente da "Comissão de Meio Ambiente, Defesa do Consumidor e Fiscalização e Controle" do Senado Federal, Presidente da CNA (Confederação da Agricultura e Pecuária do Brasil). Artigo publicado no jornal Correio Braziliense em 13 de jul. 2010. Disponivel em: <http://canaldoprodutor.com.br/comunicacao/artigos/o-bom-senso-do-relator >. Acesso em: 18/04/2011.

${ }^{2}$ Ressaltamos nossa convicção de que a participação social e o exercício pleno da cidadania são práticas indissociáveis da Educação Ambiental e da democracia.

${ }^{3}$ Mészáros nos atenta para a tendência do capital de produzir um Estado de ideologia única: "[...] Os antigos instrumentos para tratar algumas de nossas dificuldades - ainda que fossem limitados, mesmo no passado - estão hoje sistematicamente abalados e destruídos pela força inexorável do Estado, em nome do interesse na perpetuação do domínio do capital, com a ajuda da conformidade ideológica e política duramente imposta. [...] É, portanto, muito importante lutar contra os esforços correntes para impor em toda parte o Estado de ideologia única, não importa o quanto ele pareça 'racional'e universalmente louvável” (MÉSZÁROS, 2004, p. 13-14). ${ }^{4} \mathrm{O}$ portal do Governo Federal na internet, ao noticiar o evento RIO+20, que ocorrerá no Rio de Janeiro em 2012, reafirma os objetivos desta conferência da ONU: "Renovar o engajamento dos líderes mundiais com o desenvolvimento sustentável do planeta, vinte anos após a Conferência das Nações Unidas sobre Meio Ambiente
} 
instrumentos de pesquisa: recolhimento de dados sobre o financiamento das campanhas eleitorais (disponíveis na internet a partir da lei $11.300 / 06^{5}$ ) dos parlamentares membros das mesas diretivas das Comissões de Meio Ambiente da Câmara dos Deputados e do Senado Federal em 2010 e 2011, assim como dos relatores do Projeto de Lei que altera o Código Florestal; investigação sobre a atuação (no tocante às questões ambientais) das empresas financiadoras das campanhas eleitorais dos parlamentares estudados; acompanhamento dos processos de discussões, votação e aprovação na Câmara (por 410 votos a favor e 63 votos contra) do relatório do deputado Aldo Rebelo (PCdoB/ SP) - que altera a legislação florestal brasileira - e análise documental deste relatório; análise de pronunciamentos de parlamentares envolvidos nas discussões acerca da revisão do Código Florestal em diferentes mídias, privilegiando as mídias oficiais da Câmara e do Senado.

Considerando que, de acordo a Constituição Brasileira, compete às comissões temáticas da Câmara dos Deputados e do Senado Federal: "discutir e votar projetos de lei; realizar audiências públicas; receber petições e reclamações; e emitir pareceres sobre a matéria de sua competência" (BRASIL, 1989), ao analisar a composição das Comissões de Meio Ambiente do Congresso Nacional, procuramos observar quais setores da sociedade estão sendo atendidos e beneficiados por estas comissões.

A escolha de focarmos nossos olhares sobre o Código Florestal e o projeto de lei que promove a sua alteração ocorreu por considerarmos que esta questão seja como uma arena de disputas onde emergem as representações de natureza dos atores envolvidos e suas visões acerca do meio ambiente, assim como as estratégias adotadas em um confronto direto no momento exato de revisão das políticas de gestão dos recursos naturais, quando poderiam ser alteradas as "regras do jogo". Outro motivo desta escolha se deu por este ser um dos temas mais importantes em votação - envolvendo as questões ambientais - no período da investigação (2010 e 2011).

Esta solidariedade de todos os iniciados, ligados entre si pela mesma adesão fundamental aos jogos e às coisas que estão em jogo, pelo mesmo respeito (obsequium) do próprio jogo e das leis não escritas que o definem, pelo mesmo investimento fundamental no jogo de que eles têm monopólio e que precisam se perpetuar para assegurarem a rentabilidade dos seus investimentos, não se manifesta nunca de modo tão claro como quando o jogo chega a ser ameaçado enquanto tal. (BOURDIEU, 2010, p. 173).

Através das informações coletadas, identificamos que, na mesa diretiva da "Comissão de Meio Ambiente e Desenvolvimento Sustentável" da Câmara dos Deputados, no ano de 2010, dos quatro parlamentares membros, dois são classificados como ruralistas pelo Departamento Intersindical de Assessoria Parlamentar (DIAP). ${ }^{6} \mathrm{O}$ Departamento classifica como integrante da bancada ruralista aquele parlamentar que, mesmo não sendo proprietário rural ou da área de agronegócios, assume sem constrangimento a defesa dos pleitos da bancada, não apenas em plenários e nas comissões, mas em entrevistas à imprensa e nas manifestações de plenário. Dos outros dois parlamentares que não foram classificados como ruralistas, um parlamentar declarou ter recebido doações de indústrias do ramo do agronegócio e o outro não explicitou de onde vieram os recursos recebidos, usando apenas o nome do Comitê Financeiro do Partido (PFL-TO).

$\mathrm{Na}$ mesa diretiva de 2011, apenas um parlamentar foi classificado como ruralista pelo DIAP. Entretanto, na lista das empresas doadoras das campanhas dos outros três parlamentares também constam empresas do ramo do agronegócio, assim como setores da indústria pesada.

No Senado Federal, como financiadoras das campanhas eleitorais dos membros da mesa diretiva da "Comissão de Meio Ambiente, Defesa do Consumidor e Fiscalização e Controle" de 2010 e 2011 aparecem menos empresas ligadas diretamente ao agronegócio e mais indústrias petroleiras e construtoras. Apenas um parlamentar é classificado como ruralista.

Constatamos que algumas empresas realizaram doações a mais de um dos candidatos observados. Também foi observado que algumas empresas financiadoras de

\footnotetext{
e Desenvolvimento (Rio-92). Serão debatidos a contribuição da 'economia verde' para o desenvolvimento sustentável e a eliminação da pobreza, com foco sobre a questão da estrutura de governança internacional na área do desenvolvimento sustentável.” Disponível em: <http://www.brasil.gov.br/noticias/arquivos/2010/01/06/ rio-20>. Acesso em: 07/10/2011.

${ }^{5}$ Os dados coletados são oficialmente divulgados pelo TSE no endereço <http://www.tse.gov.br/>.

${ }^{6}$ Disponível em: <http://www.diap.org.br/index.php/eleicoes-2010/bancadas-suprapartidarias/ruralista >. Acesso em: 20/04/2011.
} 
QUADRO 1 - EMPRESAS FINANCIADORAS DAS CAMPANHAS DOS PARLAMENTARES ELEITOS PARA A MESA DIRETORA DA COMISSÃO DE MEIO AMBIENTE DA CÂMARA DOS DEPUTADOS EM 2010 E 2011:

\begin{tabular}{|l|c|c|}
\hline RAMO DE ATIVIDADE & $\begin{array}{c}\text { NÚMERO DE EMPRESAS QUE } \\
\text { FINANCIARAM CAMPANHAS }\end{array}$ & VALOR TOTAL DOADO EM R\$ \\
\hline CONSTRUÇÃO & 07 & $355.000,00$ \\
\hline AGROPECUÁRIA & 07 & $519.500,00$ \\
\hline ENGENHARIA & 06 & $355.500,00$ \\
\hline USINAS AÇUCAREIRAS & 04 & $285.000,00$ \\
\hline CELULOSE & 04 & $173.051,06$ \\
\hline FERTILIZANTES & 04 & $75.000,00$ \\
\hline MINERAÇÃO & 03 & $220.000,00$ \\
\hline EMPREENDIMENTOS & 03 & $213.000,00$ \\
\hline IMOBILIÁRIOS & 02 & $152.000,00$ \\
\hline BANCOS & 02 & $25.000,00$ \\
\hline SEGUROS & & \\
\hline
\end{tabular}

FONTE: Dados obtidos do site do TSE (www.tse.gov.br).

QUADRO 2 - EMPRESAS FINANCIADORAS DE CAMPANHAS DOS PARLAMENTARES ELEITOS PARA A MESA DIRETORA DA COMISSÃO DE MEIO AMBIENTE DO SENADO EM 2010 E 2011:

\begin{tabular}{|l|c|c|}
\hline RAMO DE ATIVIDADE & $\begin{array}{c}\text { NÚMERO DE EMPRESAS QUE } \\
\text { FINANCIARAM CAMPANHAS }\end{array}$ & VALOR TOTAL DOADO EM R\$ \\
\hline PETRÓLEO & 08 & $53.322,78$ \\
\hline ENGENHARIA & 03 & $137.000,00$ \\
\hline CONSTRUTORAS & 02 & $82.000,00$ \\
\hline BEBIDAS & 01 & $170.000,00$ \\
\hline QUÍMICA/FARMÁCIA & 01 & $100.000,00$ \\
\hline BANCOS & 01 & $50.000,00$ \\
\hline EMPREENDIMENTOS IMOBILIÁRIOS & 01 & $12.500,00$ \\
\hline MADEIREIRA & 01 & $10.000,00$ \\
\hline COMITÊ FINANCEIRO/DIRETÓRIO ESTADUAL & 04 & $3.037 .599,11$ \\
\hline OUTROS & 15 & $268.109,19$ \\
\hline
\end{tabular}

FONTE: Dados obtidos do site do TSE: <www.tse.gov.br>

campanhas apresentam histórico de processos judiciais por descumprimento de legislação ambiental e trabalhista.

\section{Ambientalismo pragmático e o agronegócio}

Ao observar os dados expostos acima, reafirmamos a ideia de que o debate ambientalista é essencialmente político e expressa a multiplicidade dos interesses e demandas dos atores envolvidos (LOUREIRO, 2009; LEFF, 2009).

Entre os chamados ambientalistas, podemos identificar diferentes visões de natureza e projetos societários. Loureiro (2009) nos aponta um bloco que vem se apre- sentando como hegemônico neste campo, o pragmatismo ambiental, que:

[...] caracterizou-se pelo pressuposto teórico e ideológico de que os problemas estão dados e são objetivos e que a gravidade da situação exige atitudes práticas efetivas e exitosas em curtíssimo prazo pela ação conjunta de disciplinas científicas definidas como essenciais à resolução das questões. Aqui nem todas as ciências são vistas como fundamentais, mas apenas aquelas que podem oferecer respostas rápidas, eficientes e eficazes no curto prazo para os problemas que já estão identificados. (LOUREIRO, 2009, p. 40). 
Este mesmo bloco concentra-se em realizar ações pontuais para cobrir determinadas demandas, usando a ciência e os cientistas para "validarem" suas ações. Não se preocupam em rever os paradigmas ético-científicos, pois acreditam que a ciência, da forma como é atualmente conformada, é capaz de solucionar os possíveis problemas ambientais vindouros, assim como suas consequências no campo social.

Transportando este bloco de pensamento para o Poder Legislativo da República Federativa do Brasil, observamos parlamentares - e, em consequência, projetos de leis ${ }^{7}-$ que expressam este pensamento, além de uma falsa crença na ciência como sendo isenta de ideologias e veículo de uma racionalidade pura (MÉSZÁROS, 2004). Observam-se semelhanças discursivas entre grupos do "ambientalismo pragmático" e grupos de ruralistas - identificados com o agronegócio.

Como nos afirma Mendonça (2010), o agronegócio não se restringe aos proprietários rurais, tendo a agricultura atual - referindo-a a todo um processo de rápida tecnificação - se tornado avalista de um complexo sistema externo a ela e que a subordina aos interesses do grande capital industrial e financeiro. Observando as empresas que financiaram as campanhas eleitorais dos parlamentares envolvidos nas decisões ambientais, compreendemos que são setores interligados na cadeia da produção e distribuição das commodities agrícolas e industriais, que acabam se organizando para exercer pressão para que seus interesses sejam atendidos.

É fundamental sinalizar que a noção de agronegócio organizaria e instrumentalizaria a imbricação de todas as atividades econômicas direta ou indiretamente vinculadas à agricultura - ressignificada como mera "especialização em plantar e criar" -, construindo-se um poderoso complexo, de cunho bem mais comercial e financeiro, cujo peso não poderia ser aniquilado apenas por seu desempenho econômico, mas principalmente por sua influência política. (MENDONÇA, 2010, p. 219).
Considerando que o agronegócio não se restringe às propriedades rurais, mas engloba um grande segmento que atua "antes da porteira da fazenda" - realizando pesquisas e experimentações para garantir maior eficiência produtiva (sementes "melhoradas", corretivos, fertilizantes, vacinas, rações, medicamentos, tratores), assim como mecanismos especializados de crédito rural e ações de marketing no campo - e "depois da porteira da fazenda" - armazenamento, transporte, processamento, embalagens, industrialização e distribuição (MENDONÇA, 2010, p. 218-219), a Associação Brasileira do Agronegócio (ABAG) reúne entre suas associadas ${ }^{8}$ um grande número de empresas públicas e privadas, incluindo empresas financiadoras da campanha eleitoral dos parlamentares estudados, objetivando "promover ações articuladas entre os diferentes elos das cadeias produtivas, com a preocupação de evitar divergências com as demais entidades ligadas ao complexo industrial brasileiro, por meio de ações conjuntas e sinérgicas".

Ainda segundo Mendonça (2010), alguns setores do patronato rural, especialmente os ligados à Sociedade Nacional de Agricultura (SNA), desde os anos 1970, avançam em novas frentes para a ampliação de seus espaços e sua influência política: a ecologia, o ensino e a imbricação ao Estado em sua dimensão regional. Desta forma, a SNA passa a "advogar para si o papel de 'pioneira' e 'legítima' representante da causa ambiental" (MENDONÇA, 2010, p. 96) ${ }^{10}$, disputando o "poder" de conceituar o que é ser "ambientalmente correto".

Em entrevista concedida à "TV Câmara" (06/04/2011) sobre as divergências no debate sobre as alterações do Código Florestal brasileiro (Projeto de Lei $n^{\circ} 1.876 / 99$ ), o deputado Reinhold Stephanes afirma:

A discussão vira muito ideológica, vira muito politizada ao invés de ser uma discussão que traga racionalidade para aqueles pontos que precisam ser efetivamente conciliados. (informação verbal) ${ }^{11}$

\footnotetext{
${ }^{7}$ Aqui dirigimos uma crítica ao parecer do Deputado Aldo Rebelo ao Projeto de Lei no 1.876/99 e apensados, que altera o Código Florestal Brasileiro.

${ }^{8}$ Encontram-se associadas: Banco do Brasil S.A.; Banco Itaú BBA S/A.; Banco Santander S.A.; Empresa Brasileira de Pesquisa Agropecuária - EMBRAPA; Globo Comunicação e Participações S.A.; Vale S/A. (FCA - Ferrovia Centro Atlântica) e outras. Disponível em <http://www.abag.com.br/>. Acesso em: 20/04/2011.

${ }^{9}<\mathrm{http}: / /$ www.abag.com.br/>.

${ }^{10} \mathrm{O}$ envolvimento da SNA com a questão ambiental assegurou-lhe, nesta época, um espaço politicamente "neutro". "O apogeu da participação da SNA na questão preservacionista foi marcado pela convocação, em 1991, do Painel sobre Meio Ambiente e Desenvolvimento, destinado a organizar, sob sua direção, os grupos ambientalistas que atuariam na Eco-92, como ficou conhecida a II Conferência das Nações Unidas para o Meio Ambiente e o Desenvolvimento, realizada na cidade do Rio de Janeiro em 1992.” (MENDONÇA, 2010, p. 98).

${ }^{11}$ Reinhold Stephanes, economista e deputado federal pelo PMDB/PR. Foi ministro da Agricultura, Pecuária e Abastecimento. É membro da Frente Parlamentar Ambientalista e membro do GT sobre o Código Florestal. Entrevista completa disponivel em: $<$ http://www2.camara.gov.br/tv/materias/BRASIL-EM-DEBATE/195375DEP.-REINHOLD-STEPHANES-\%28PMDB-PR\%29-E-DEP.-MARCIO-MACEDO-\%28PT-SE\%29:-CODIGO-FLORESTAL.html>. Acesso em: 18/04/2011.
} 
A partir desta afirmação, pontuamos as diferenças existentes entre dois tipos de racionalidades aqui consideradas, a econômica e a ecológica: "Enquanto a racionalidade econômica aponta que estamos vivenciando apenas uma crise ambiental, a racionalidade ecológica a define como uma crise muito mais abrangente, pois seria civilizacional" (LAYRARGUES, 1998, p. 35).

Desta forma, um pensamento estritamente econômico sobreporia os imperativos econômicos aos ambientais por estes serem considerados como uma simples variável de mercado. Como exemplo, a Associação Brasileira do Agronegócio (ABAG), em seu portal na internet, afirma: "agronegócio é sustentabilidade".

Em 2008, na comemoração de seu $15^{\circ}$ aniversário, a ABAG abraçou com mais afinco o conceito do desenvolvimento sustentável. Juntamente com outras entidades do setor, montou o Instituto para o Agronegócio Responsável (ARES). ${ }^{12}$

O Instituto ARES disponibiliza na internet um glossário socioambiental, com o intuito de "homogeneizar e divulgar" este importante tema, pois "percebemos que há muita confusão e diferentes interpretações de termos utilizados nas ciências socioambientais." A definição de sustentabilidade para o glossário se expressa como sendo:

Qualidade, característica ou requisito do que é sustentável. Num processo ou num sistema, a sustentabilidade pressupõe o equilíbrio entre "entradas" e "saídas", de modo que uma dada realidade possa manter-se continuadamente com suas características essenciais. $\mathrm{Na}$ abordagem ambiental, a sustentabilidade é um requisito para que os ecossistemas permaneçam iguais a si mesmos, assim como os recursos podem ser utilizados somente com reposição e/ou substituição, evitando-se a sua depleção, de maneira a manter o equilíbrio ecológico, uma relação adequada entre recursos e produção, e entre produção e consumo. ${ }^{13}$

A definição acima - elaborada por setores do agronegócio - expressa uma visão pragmática do meio ambiente, que aparece claramente a serviço do mercado. Desta forma, um artigo publicado no jornal $O$ Estado de São Paulo, divulgado através do portal do Instituto ARES em 21 de março de 2011, informa que o "Governo planeja duplicar área de florestas plantadas no País em 10 anos" para transformar o país em uma "potência florestal" através da participação dos produtos de origem florestal no mercado internacional - papel, painéis de madeira e resíduos para a produção de energia. ${ }^{14}$

A questão colocada por Leff (2009) como um projeto alternativo de sustentabilidade aponta a necessidade de descentralização da economia e desconcentração do poder para efetivar processos de democratização ambiental centrado na organização e na autogestão da sociedade. Mészáros (2004) aponta que o controle sociometabólico de indivíduos livremente combinados torna possível a sustentabilidade de uma nova ordem produtiva, pois "sustentabilidade equivale ao controle consciente do processo de reprodução sociometabólica pelos produtores livremente associados (o que, evidentemente, é o único meio viável de autocontrole)." (MÉSZÁROS, 2004, p. 44, grifos do autor).

$\mathrm{O}$ embate entre estas duas concepções de sustentabilidade traz à tona dois projetos societários opostos: um busca que "uma dada realidade possa manter-se continuadamente com suas características essenciais" e o outro busca uma nova ordem produtiva, com a desconcentração do poder para uma verdadeira democratização na gestão dos recursos naturais.

As estratégias do "antiecologismo" acabam por surgir quando, neste embate, em nome de um suposto "consenso" (MÉSZÁROS, 2004), um projeto societário procura anular e desqualificar o outro.

\section{O antiecologismo}

Sendo o movimento ambientalista de caráter difuso e multissetorial, verificou-se que, apesar de manterem uma prática antiecológica, alguns grupos facilmente conseguem se "vestir de verde" para conseguirem benefícios e manter o discurso sintonizado com o meio ambiente.

Através da observação de casos que ocorrem no momento em que as operações da sustentabilidade com-

\footnotetext{
$12<$ http://www.abag.com.br/>.

$13<$ http://www.institutoares.org.br/glossario.asp $>$.

${ }^{14}$ Artigo de autoria de Marta Salomon. Disponível em: <http://www.institutoares.org.br/fpd_informa_nota.asp?cod=1191\&q=1GV2RQM34P\&top=TOP\%2010>. Acesso em: 21/04/2011.
} 
prometem a continuidade de interesses ecologicamente incorretos (LAYRARGUES, 2010) e abalam as "regras do jogo" (BOURDIEU, 2010), foi constatada a existência de um "movimento antiecológico" inserido em aparelhos do Estado e com influências políticas.

Movidos por interesses privados, estes grupos ou indivíduos ${ }^{15}$ utilizam como estratégias: a desinformação; a distorção de descobertas científicas; a má interpretação de dados - "para construir uma certa visão do mundo e sustentar uma agenda política" (EHRLICH, 1996, p. 11, tradução nossa); se autointitulam promotores do desenvolvimento, geradores de emprego, divisas e produtos (LAYRARGUES, 1998, p. 79); se organizam para exercer pressão a favor da flexibilização da legislação ambiental e do desmonte do aparato público administrativo para a gestão ambiental, assim como a redução de verbas públicas para a fiscalização; adotam a política do "fato consumado" para a aprovação de leis a seu favor; atacam movimentos ambientalistas, desqualificando-os pretensamente em prol da "soberania nacional" e do "interesse social relevante", gerando confusão e confundindo a opinião pública, deliberadamente.

Ainda segundo Ehrlich (1996), por meio da massificação, uma enxurrada de sentimentos "antiecológicos" ganhou aura de credibilidade, trabalhando para disseminar o descontentamento entre aqueles que de alguma forma se sentem prejudicados por regulamentações ambientais. Vinculados a lobbies industriais, a parlamentares e a meios de comunicação, estes grupos são capazes de aprovar qualquer alteração legislativa. (EHRLICH, 1996).

Diante desta ameaça ao próprio "jogo" (BOURDIEU, 2010), quando estão em debate as suas regras - a reforma do Código Florestal e a reforma política, por exemplo -, observa-se que grupos com o mesmo grau de interesses iniciam um movimento de articulação para ocupar espaços e avançar sobre a oposição. Mesmo que estes grupos estejam habituados a se relacionarem entre si sob a lógica da concorrência capitalista, nestes momentos de grandes revisões tendem a se unificar. Como exemplo, a ABAG (Associação Brasileira do Agronegócio), criada em 1993 para organizar entidades representativas de todos os segmentos do setor do agronegócio, divulga em seu portal na internet:
AABAG promove ações articuladas entre os diferentes elos das cadeias produtivas, com a preocupação de evitar divergências com as demais entidades ligadas ao complexo industrial brasileiro, por meio de ações conjuntas e sinérgicas. ${ }^{16}$

A senadora Kátia Abreu, vice-presidente da Comissão de Meio Ambiente do Senado Federal, presidente da Confederação da Agricultura e Pecuária do Brasil (CNA) e forte representante do setor do agronegócio, através do vídeo "Ajude-nos nesta missão", vem a público pedir que empresas do setor agrário e setores associados façam doações em dinheiro para campanhas eleitorais dos candidatos da bancada ruralista no Congresso, a fim de continuarem tendo os seus interesses representados no legislativo a partir de $2011 .{ }^{17}$

Neste mesmo vídeo, a senadora deixa a entender que o maior objetivo destas doações a serem feitas pelo setor do agronegócio seria a pauta de projetos de lei a ser colocada como prioridade em 2011 para votação, tanto na Câmara como no Senado, sendo o Código Florestal o maior desafio.

As posturas antiecológicas de parlamentares no interior do Congresso Nacional saltam à vista em momentos em que a contradição entre o discurso de defesa da natureza e a visão da natureza como um entrave aos seus interesses é explicitada:

\begin{abstract}
"No Brasil, a mão que produz é a mesma que preserva". (Senadora Kátia Abreu, através do portal que dirige na internet, "Canal do Produtor"18).
\end{abstract}

\begin{abstract}
“A reserva legal é um corpo estranho. Não há a menor possibilidade de os Estados Unidos aceitarem uma unidade de conservação dentro de uma unidade de produção. O governo brasileiro deveria estar permitindo o aumento das áreas produtivas e o barateamento do alimento. Fizemos tudo isso não foi deitado em rede. Foi trabalhando, foi desmatando sim, foi transformando cobertura florestal em arroz." (Senadora Kátia Abreu, março de 2011, em pronunciamento no Senado). ${ }^{19}$
\end{abstract}

\footnotetext{
${ }^{15}$ Compõem o que Paul Ehrlich denomina de brownlash, “porque eles ajudam a alimentar uma reação contra as 'políticas verdes',” (EHRLICH, 1996, tradução nossa).

${ }^{16}$ Disponível em: <http://www.abag.com.br/index.php?mpg=01.01.00>. Acesso em: 20/07/2011.

${ }^{17}$ Vídeo disponível em <http://www.youtube.com/watch?v=EfHSj4yjg2g $>$. Acesso em: 20/05/2011.

$18<$ http://www.canaldoprodutor.com.br/codigoflorestal $>$.

${ }^{19}<$ http://oglobo.globo.com/pais/mat/2011/03/29/katia-abreu-critica-proposta-de-aldo-rebelo-para-reforma-do-codigo-florestal-924114451.asp\#ixzzlaC721SbT>.
} 
"O termo 'reserva legal', que consta do Código Florestal, só existe aqui. É uma jabuticaba jurídica, que não agrega nenhuma função ambiental. Foi-nos imposta por essas ONGs, que não se mostram tão indignadas com a degradação ambiental em seus próprios países. Se 'reserva legal' fosse unanimidade, não existiria só no Brasil.” (Senadora Kátia Abreu). ${ }^{20}$

Em entrevista concedida à "TV Câmara", em 06/04/2011, ao falar sobre as divergências no debate sobre as alterações do Código Florestal Brasileiro (Projeto de Lei $\left.{ }^{\circ} 1.876 / 99\right)$, o deputado Reinhold Stephanes ${ }^{21}$ afirma:

Num dos debates que eu participei há pouco tempo com representantes de uma das grandes organizações internacionais que comandam um pouco no Brasil esta questão do meio ambiente, em vinte minutos ele falou oito vezes em Karl Marx, o nosso grande filósofo, o nosso grande humanista, evidentemente uma pessoa que merece todo respeito. Só que nós não estamos discutindo modelos de produção marxistas ou comunistas. Nós temos um modelo de produção. Então, quer dizer, a discussão vira muito ideológica, vira muito politizada ao invés de ser uma discussão que traga racionalidade para que aqueles pontos que precisam ser efetivamente conciliados.

Deixar de discutir o modelo de produção no qual estamos inseridos em nome de um suposto "estado de emergência" denota o pouco interesse em rever as "regras do jogo" e somente contribui para a tomada de decisões paliativas que reforçam os desequilíbrios não só na esfera ambiental, mas também nas esferas social e econômica. Além disso, o tom da fala aponta para a desqualificação do discurso ambientalista, situando-o como exógeno e em descompasso com os interesses de um suposto "modelo de produção" já definido. Outro aspecto desta fala é a polarização do debate, qualificando o argumento ambientalista como "politizado" e "ideológico".

Quanto aos relatores, na Câmara e no Senado, do projeto de lei que altera o Código Florestal, o deputado Aldo Rebelo (PCdoB/SP), que obteve grande apoio dos parlamentares que foram ao plenário da Câmara aprovar o projeto (a aprovação ocorreu por 410 votos a favor e 63 votos contra), recebeu em 2010 recursos das seguintes em- presas: Alesat Combustíveis S.A.; Alusa Engenharia Ltda.; Apsen Farmacêutica S.A.; Biolab Sanus Farmacêutica Ltda.; Caltins - Calcário Tocantins Ltda.; Construções e Comércio Camargo Correia S.A.; Cooperativa de Cafeicultores e Agropecuaristas; Cooperativa de Cafeicultores e Citricultores de São Paulo; Cooperativa de Crédito Rural - Cocapec; Cooperativa de Crédito Rural - Credicitrus; Cooperativa Regional de Cafeicultores em Guaxupé Ltda. Cooxupe; Empresa Brasileira de Aeronáutica - EMBRAER; Gerdau Comercial de Aços S/A.; Gran Petro Distribuidora de Combustíveis; Libbs Farmacêutica Ltda.; Usiminas Mecânica S.A..

Das empresas que realizaram "doações" à campanha de Aldo Rebelo, comentaremos a atuação da Construções e Comércio Camargo Correia S.A. e da Gerdau Comercial de Aços S/A.

A Camargo Corrêa atua nos setores de construção e engenharia, calçados, têxteis, infraestrutura e imóveis. Em março de 2009 (cerca de um ano antes das eleições para deputados), a Polícia Federal (PF) deu prosseguimento a 16 mandados de busca e apreensão e 10 mandados de prisão de diretores e funcionários da empresa, na operação que ficou amplamente conhecida como "Castelo de Areia". Os principais crimes investigados pela PF foram evasão de divisas, operação de instituição financeira sem autorização, formação de quadrilha, lavagem de dinheiro e fraude a licitações. Em janeiro de 2010, o Superior Tribunal de Justiça (STJ) de Brasília suspendeu a ação penal contra os diretores da Camargo Corrêa. Em março de 2011, a imprensa nacional noticiou a revolta dos operários na Usina Hidrelétrica de Jirau contra as empresas que controlam a barragem, dentre elas a Camargo Corrêa. As denúncias eram de que os mais de 15 mil operários da obra estavam em situação de superexploração, com salários extremamente baixos, longas jornadas e péssimas condições de trabalho, que existia epidemia de doenças dentro da usina (sem atendimento adequado de saúde), que o transporte dos operários era de péssima qualidade e ainda sofriam com a falta de segurança. Em 28 de setembro de 2011, a revista Veja anunciou que a Polícia Civil de Rondônia concluiu o inquérito sobre a revolta dos operários da Usina Hidrelétrica de Jirau e que se tratava de "um movimento criminoso travestido de greve". Afirmou ainda que os líderes do grupo responderão pelos crimes de incêndio, dano qualificado, furto e formação de quadrilha.

\footnotetext{
${ }^{20}<\mathrm{http}$ ://www.canaldoprodutor.com.br/comunicacao/artigos/de-quintal-reserva-legal $>$. Acesso em: outubro de 2011.

${ }^{21}$ Entrevista completa disponível em: <http://www2.camara.gov.br/tv/materias/BRASIL-EM-DEBATE/195375-DEP.-REINHOLD>. Acesso em: 20/05/2011.
} 
O grupo Gerdau também apresenta histórico de envolvimento com trabalho escravo:

A Amazônia brasileira produz o melhor ferrogusa do mundo, usado principalmente na produção de peças automotivas. É um mercado que movimenta 400 milhões de dólares anuais somente na região Norte $-2,2$ milhões de toneladas/ano - e tem como principal compradora a indústria siderúrgica dos Estados Unidos. Esse gusa alimenta um mercado de alta tecnologia, o dos aços especiais. A produção, contudo, tem na base de sua cadeia de valor uma das piores formas de exploração humana: o trabalho escravo, que acontece em carvoarias localizadas na floresta amazônica. [...] As carvoarias da Amazônia são controladas por 13 siderúrgicas com sede no Maranhão e no Pará. Algumas siderúrgicas são de propriedade de gigantes da economia, com atuação em quase todo o território brasileiro e também no exterior. $\mathrm{O}$ grupo Queiroz Galvão é dono da Simasa e da Pindaré. O grupo GERDAU controla a Margusa. Simasa e Margusa são acusadas pelo Ministério Público do Trabalho de usarem mão de obra escrava em carvoarias ilegais. Esse carvão é usado na produção do ferro-gusa exportado aos Estados Unidos para a produção de aço, que por sua vez é matéria-prima de automóveis e diversos outros produtos. (Observatório Social em Revista, n. 6, jun. 2004). ${ }^{22}$

O deputado Aldo Rebelo, entretanto, em seu parecer ao Projeto de Lei que altera o Código Florestal (PL 1.876/99) afirma:

O presente relatório pretende demonstrar que as escolhas morais e ideológicas no debate contemporâneo sobre a natureza e o meio ambiente revelam, na verdade, os interesses concretos das nações ricas e desenvolvidas e de suas classes dominantes na apropriação dos bens naturais já escassos em seus domínios, mas ainda abundantes entre as nações subdesenvolvidas ou em processo de desenvolvimento. [...] Malthus foi derrotado, mas sua ideologia sobre a divisão da riqueza permaneceu de pé, e a ideia de que "não há lugar para os pobres no banquete da natureza" é a matriz, o núcleo duro, que orienta todos os movimentos que de algum modo procuram restringir o crescimento econômico e populacional em nome dos limites do planeta. Assim como para Malthus, nos primórdios do capitalismo a questão era garantir a abundância dos ricos, que poderia ser posta em risco pelo crescimento populacional, todos os movimentos posteriores, que tentam de algum modo impor limites ao crescimento mundial, particularmente dos países pobres, partilham do mesmo princípio. (REBELO, 2010).

Na continuação do parecer, Rebelo segue criticando algumas correntes ambientalistas ("É cada vez mais agressiva a corrente ambientalista que tende a responsabilizar moralmente o antropocentrismo como fonte primária e maligna dos desastres ambientais") e classifica esta mesma corrente como antropofóbica, pois, segundo ele, descarta como irrelevante a situação de milhões de seres humanos em condições abjetas de existência material e espiritual.

Milhões que não dispõem da segurança do pão de cada dia, das condições mínimas de higiene e saúde, do acesso à educação e à segurança individual e coletiva, do conforto da família e dos amigos, da proteção do Estado nacional ou da liberdade política e religiosa. (REBELO, 2010).

Rebelo ataca as correntes ambientalistas em geral, aproveitando-se de suas fragilidades e contradições para afirmar que os ambientalistas não se importam com os seres humanos, que não pensam no desenvolvimento social do país, no acesso à educação, etc., apelando para um "nacionalismo" que exalta costumes e tradições do meio rural ao mesmo tempo em que defende (considerando como sendo "natural") as "reduzidas moradias urbanas".

O senso comum recebeu com merecida estupefação a sentença condenatória contra o boi. Logo ele, o animal presente no imaginário brasileiro como símbolo ao mesmo tempo da força, da elegância, do trabalho e de múltiplas utilidades. O boi do carro de boi; o boi do arado; o boi da cara preta da canção de ninar; o boi dos folguedos folclóricos - do Reisado, do Bumba-meu-Boi, do Caprichoso e Garantido. Creio até que o boi é o animal de estimação preferido de muitos brasileiros, e ocuparia o lugar do cão e do gato, fosse mais simples alimentá-lo e acomodá-lo no reduzido espaço das moradias urbanas. (REBELO, 2010).

\footnotetext{
${ }^{22}$ Disponível em: <http://www.reporterbrasil.org.br/documentos/escravos_aco.pdf>. Acesso em: 08/10/2011.
} 
Adiante, em tom de "piada", critica o rigor da legislação ambiental, vinculando a existência da corrupção à própria existência da legislação a ser cumprida. Neste trecho, Rebelo deixa de exaltar o "homem urbano" e considera este "homem urbano em geral" (abstrato) como sendo alheio à problemática do meio rural:

Assim vai o nosso agricultor, notificado, multado, processado, embargado na sua propriedade, sentenciado, e mal arranca da terra o seu sustento e o da sua família e já se vê sustentando o fiscal ambiental, o soldado, o delegado, o oficial de justiça, o promotor, o desembargador, o advogado, o banqueiro e a ONG que inspirou o seu infortúnio. Da cidade, o homem urbano olha com desdém e desprezo a sua labuta. Se um morro desliza, se o rio poluído invade as cidades, se a enchente causa transtornos, do conforto do seu automóvel ou do apartamento que despeja os resíduos no curso d'água, ele aponta o culpado: aquele sujeito que está plantando uma lavoura, ou criando uma vaca ou uma cabra em algum lugar distante no campo brasileiro. (REBELO, 2010).

Em seguida, Rebelo critica o chamado "ecoanarquismo" e o novo mercado surgido com a atuação das ONGs ambientalistas (nacionais e internacionais), perfeitamente encaixadas no modelo capitalista:

O ambientalismo funcionou como rota de fuga do conflito ideológico entre o capitalismo e o socialismo. Os desiludidos de ambas as ideologias vislumbraram no ambientalismo um espaço a partir do qual poderiam reorganizar suas crenças e seus projetos de vida e se juntar a tantos outros que por razões diferentes fizeram da bandeira verde um novo modo ou meio de vida. Ao ecologismo ideológico juntou-se o profissional e empreendedorista. Consultorias concedidas por ONGs que contratam e são contratadas, recebem financiamento interno e externo, público e privado, funcionam dirigidas por executivos profissionais que já representam atividade nada desprezível no setor de serviços. (REBELO, 2010).

Quando o tema é a Amazônia, Rebelo justifica a sua depredação alegando que a floresta nunca foi "boazinha" com os seres humanos e por isso os seres humanos não precisam ser "bonzinhos" com a floresta. Neste trecho, a "natureza" aparece como um inimigo a ser derrotado, assim como os ambientalistas - que, para Rebelo, resumem-se às ONGs.

\begin{abstract}
A harmonia entre os chamados povos da floresta e o meio em que vivem - na verdade sobrevivem - não passa de ficção produzida para filmes como Avatar, de James Cameron, que levam às lágrimas plateias confortavelmente instaladas em modernas salas de cinema dos shopping-centers, cercadas de praças de alimentação, onde ao estalar de dedos aparece como por mágica qualquer tipo de comida desejada pelo emocionado espectador. Provavelmente a maioria, ao saborear o suculento bife ou a fresca salada, não faz a menor ideia da luta entre o homem e meio ambiente na Amazônia, nas quantidades de demandas por alimento saudável, livres de parasitas de todos os tipos que disputam com o ser humano o direito à vida.

[...] A Amazônia jamais foi um santuário da natureza. Ocupada há pelo menos 11 mil anos, a região aparece na vasta crônica da conquista e consolidação do território do Brasil como cinta verde da agricultura que permitiu a fixação do homem em comunidades perenes, estancando o nomadismo padrão dos coletores dos frutos da natureza. (REBELO, 2010)
\end{abstract}

Neste momento, Rebelo abandona sua "luta" pelo desenvolvimento como forma de promover melhorias nas condições de vida da população da Amazônia, deixando claro que a infraestrutura a ser construída visa ao crescimento das atividades exploratórias na região, que são destinadas principalmente à exportação:

[...] Enquanto o Ministério Público e os órgãos ambientais pressionam os pequenos, médios e grandes produtores do Sul e do Sudeste, é na Amazônia Legal, na faixa de transição entre o Cerrado e o bioma Amazônico, que as ONGs e suas campanhas milionárias procuram interditar a infraestrutura - rodovias, ferrovias, hidrovias, portos - destinada ao crescimento da agricultura, pecuária e mineração. (REBELO, 2010).

Entretanto, Rebelo retoma sua preocupação com os "pobres" ao pensar na possibilidade de frear o "crescimento do país" por causa das mudanças climáticas:

Ninguém questiona o fato de que o clima na Terra está em permanente mudança. [...] Não há consenso, porém, sobre até que ponto as mudanças climáticas recentes decorrem da ação humana ou de processos cujos ciclos podem ser medidos em centenas, milhares ou milhões 
anos. [...] Diante do elevado grau de incerteza da maioria das hipóteses, adotar planos de contingência para todos os cenários imagináveis, mesmo os mais catastróficos e improváveis, baseados na hipótese de que "o planeta se encontra à beira do colapso em decorrência da ação humana" e de que "existem soluções de baixo custo", podem implicar em custos sociais e econômicos desproporcionais aos possíveis e mesmo improváveis ganhos, principalmente se consideramos a tendência de que a conta pesará mais sobre os pobres. (REBELO, 2010).

Finalmente, o deputado encerra seu parecer defendendo os "excluídos" e reafirmando os "horrores" praticados em nome da lei e da proteção do meio ambiente:

A memória das centenas de depoimentos colhidos permanecerá para os estudiosos, os legisladores, os produtores ou a simples curiosidade pública como um acervo dos horrores que foram praticados em nome da lei e da proteção do meio ambiente. Mas ela ficará também como depoimento eloquente de amor à natureza e ao País por parte daqueles que sempre estiveram ausentes quando das decisões sobre seus destinos e sobre o destino da natureza e do Brasil. (REBELO, 2010)

O parecer do deputado Aldo Rebelo apresenta-se, desta forma, como um grande e forte exemplo do fenômeno antiecologismo dentro do Congresso Nacional.

\section{Considerações finais}

A Educação Ambiental Crítica surge de forma a contestar alguns dos paradigmas vigentes, comprometendo-se com a transformação societária (LOUREIRO, 2009). Desta forma, trabalha para a redução das desigualdades e desconcentração dos poderes de decisão, retirando o capital político (BOURDIEU, 2010) das mãos de um pequeno grupo que "é tanto menos contrariado quanto mais desapossados de instrumentos materiais e culturais necessários à participação ativa na política estão os simples aderentes - sobretudo o tempo livre e o capital cultural". (BOURDIEU, 2010, p. 164).

Tendo em conta que a chamada "crise ambiental" em que vivemos é vista por estas tendências ambientalistas críticas como sendo um dilema civilizacional que engloba várias crises - civilizatória, moral, política, tecnológica, ambiental, entre outras - que expressam, em última instância, as diversas patologias do capitalismo (LOUREIRO, 2006), ao voltarmos nossos olhares para o Congresso Nacional Brasileiro observamos estratégias que trabalham para encobrir a perspectiva crítica da crise ambiental e disseminar a sua visão única acerca das possíveis soluções, de forma que não desestabilize a ordem vigente e os seus percentuais de lucro.

Sendo assim, diversos grupos - que sustentam graus de heterogeneidade entre si - adotam, de formas mais ou menos articuladas, diversas estratégias de "antiecologismo", na tentativa de perpetuar os seus poderes sobre os "Poderes Públicos" (as administrações do Estado).

$\mathrm{O}$ estudo do fenômeno antiecologismo nos aponta mais uma vez o caráter conflituoso que a "questão ambiental" carrega em si, pois trata, enfim, da quantidade e qualidade da provisão dos "bens públicos" ou "bens comuns" (água, ar, florestas, etc).

Se considerarmos o poder legislativo como criador de normas e regras que balizarão e instituirão modos de agir legalmente em sociedade, a própria existência deste fenômeno neste contexto institui e "legaliza" o antiecologismo nesta sociedade, o que nos ajuda a refletir sobre alguns limites da ação educativa na tarefa da conscientização ambiental.

Pensamos que para a Educação Ambiental (EA) ser realmente transformadora deve atuar de forma a trazer elementos para que cada vez mais pessoas possam discernir as questões relativas ao meio ambiente e ter dimensão sobre as consequências dos seus posicionamentos e escolhas. Desta forma, a EA deve contribuir para o entendimento das contradições da sociedade e da dinâmica das lutas políticas que são travadas diariamente. 


\section{Referências}

BOURDIEU, Pierre. O poder simbólico. Rio de Janeiro: Bertrand Brasil, 2010.

BRASIL. Constituição, 1988. Constituição da República Federativa do Brasil, 1988. São Paulo: Ed. Revista dos Tribunais, 1989.

BRANCALION, Pedro Henrique Santin; RODRIGUES, Ricardo Ribeiro. Implicações do cumprimento do Código Florestal vigente na redução de áreas agrícolas: um estudo de caso da produção canavieira no Estado de São Paulo. Biota Neotropica, Campinas, v. 10, p. 63-66, 2010.

EHRLICH, Paul R. Betrayal of science and reason: how anti-environmental rhetoric threatens our future. Washington: Island Press, 1996.

FREIRE, Paulo. Pedagogia do oprimido. Rio de Janeiro: Paz e Terra, 2005.

GADOTTI, Moacir. Pedagogia da práxis. São Paulo: Cortez/ Instituto Paulo Freire, 2004.

GALETTI, M.; PARDINI, R.; DUARTE, J.; SILVA, V.; ROSSI, A.; PERES, C. Mudanças no Código Florestal e seu impacto na ecologia e diversidade dos mamíferos no Brasil. Biota Neotropica, Campinas, v. 10, pp. 47-52, 2010.

LAYRARGUES, Philippe Pomier. A cortina de fumaça: o discurso empresarial verde e a ideologia da racionalidade econômica. São Paulo: Annablume, 1998.

Quando os ecologistas incomodam: uma caracterização preliminar do antiecologismo. Artigo apresentado à Anppas em outubro de 2010.
LEFF, Enrique. Ecologia, capital e cultura: a territorialização da racionalidade ambiental. Petrópolis: Vozes, 2009.

LOUREIRO, Carlos Frederico B. O movimento ambientalista e o pensamento crítico: uma abordagem política. Rio de Janeiro: Quartet, 2006.

. Trajetórias e fundamentos da educação ambiental. São Paulo: Cortez, 2009.

MARTINELLI, L.; JOLY, C.; NOBRE, C.; SPAROVEK,G. A falsa dicotomia entre a preservação da vegetação natural e a produção agropecuária. Biota Neotropica, Campinas, v. 10, pp. 323-330, 2010.

MENDONÇA, Sonia Regina de. O patronato rural no Brasil recente (1964-1993). Rio de Janeiro: Editora UFRJ, 2010.

MÉSZÁROS, István. O poder da ideologia. São Paulo: Boitempo, 2004.

REBELO, Aldo. Parecer do relator ao Projeto de Lei $n^{\circ}$ 1.876/99 e apensados. Brasília, Sala das Sessões, 8 jun. 2010. Disponível em: <http://www.camara.gov.br/sileg/integras/777725.pdf $>$. Acesso em: 18/04/2011.

TUNIDISI, José Galizia; TUNDISI, Takako Matsumura. Impactos potenciais das alterações do Código Florestal nos recursos hídricos. Biota Neotropica, Campinas, v. 10, pp. 67-75, 2010.

TOLEDO, L.; CARVALHO-E-SILVA, S.; SÁNCHEZ, C.; ALMEIDA, M.; HADDAD,C. A revisão do Código Florestal Brasileiro: impactos negativos para a conservação dos anfíbios. Biota Neotropica, Campinas, v. 10, pp. 35-38, 2010.

Recebido em setembro de 2011. Aceito em novembro de 2011. Publicado em junho de 2012. 